\title{
A STRUCTURAL EQUATION MODEL ON RESEARCH SKILLS
}

\author{
Romeo S. Berba, PhD ${ }^{1}$, Elleine Rose A. Oliva, EdD
}

Article DOI: https://doi.org/10.36713/epra9388 DOI No: 10.36713/epra9388

\begin{abstract}
This research aimed to find the best model for research skills. Its goal is to ensure that the exogenous variables of reading, writing, and learning strategies substantially correlate with the endogenous variable of research skills. In addition, to establish the optimal model on research skills, non-experimental correlational research design and structural equation models were used. However, 407 college students from public and private colleges and universities in Region $X$ were chosen using a stratified random selecting technique. The mean, Pearson $r$, regression, and structural equation models were used (SEM). The study's fifth model adapted outcome shows that exogenous factors have a significant association with endogenous variables. Exogenous variables, on the other hand, have a high descriptive quality. Reading strategies include pre-reading, during reading, and after reading; writing strategies include pre-writing, when writing, and revision; learning strategies include planning stage, doing stage, what I want to do well, and my feeling about the task; and the endogenous variable acquired a high descriptive level of research skills, which included reading and understanding research literature, collecting research data, programming skills, and analyzing a data set, scientific communication, and understanding of the field and the research process.
\end{abstract}

KEYWORDS: research, reading strategies, writing strategies, learning strategies, research skills, structural model, Philippines

\section{INTRODUCTION}

Teaching is difficult when it comes to developing research skills because most students are deficient and inexperienced in conducting effective research (Gyuris 2018). Acquiring this skill demonstrates conducting research and generating new knowledge (Azmi and Daud 2019). However, the study established that the students lacked acquired research skills (Akuegwu and Nwi-ue 2018). As a result, the quality of their generated research deteriorates in nondiscovery and acquisition of new knowledge that contributes to the advancement of life and society (Nauman 2017). Additionally, research ability provides unique insight into discovering novel ideas that can help people better understand a situation (Ezugwu and Jebson 2019).

However, the student's practice of research skills provides them with the necessary knowledge and abilities to engage in research and publication (Dorimana, Ndihokubwayo, and Uworwabayeho 2021). Additionally, there is a significant correlation between reading, writing, and acquiring research strategies. Thus, academic reading and writing help students develop the research skills necessary to become researchers. Additionally, they honed their research abilities to generate high-quality research output (Castillo-Martnez and Ramrez-Montoya 2021). Additionally, the use and teaching of active learning strategies aid in developing writing and research skills. As a result, developing research skills will help you improve your writing and research abilities (Deraney and Hamdan Alghamdi 2018).

In this regard, some studies on research practice have been conducted, but they are shown from afar and focus exclusively on its analysis, development, improvement, validation, and application. Additionally, no research or model focuses on the relationship and influence of reading, writing, and learning strategies on research practice.

\section{RESEARCH OBJECTIVES}

This research aimed to find the best model of research skills for reading, writing, and learning strategies. In this regard, the researcher hopes to respond to the following precise goal:

1. Know the reading strategy level when evaluated according to:
1.1. Pre-reading;
1.2. During-reading and
1.3. After-reading

2. Determine the writing strategy level when evaluated according to:
2.1. Pre-writing;
2.2. When-writing and
2.3. Revision

3. Determine the level of learning strategy if analyzed according to:
3.1. Planning stage;
3.2. Doing stage
3.3. Reflection stage;
3.4. How I Know if I Will Succeed
3.5. Why I Want to Do It Well and
3.6. My Feelings About the Task

4. Know the level of research skills of the students when evaluated according to:

Literature;

4.1. Reading and Understanding Research

4.2. Collecting Research Data

4.3. Programming Skills;

4.4. Analyzing and Interpreting Research Data

4.5. Scientific Communication

4.6. Understanding of the Field and the

Research Process and 
4.7. Confidence in Your Research Related Activities

5. Identify the significant relationship between reading, writing, learning strategies and research skills.

6. State the significant effect of the reading, writing and learning strategies on research skills

7. Know the best model suited to research skills.

\section{HYPOTHESIS}

This study's null hypotheses were developed and tested at a significance level of 0.05 in which:

1. There is no connection between:

1.1 reading strategies,

1.2 writing strategies, and

1.3 learning strategies.

2. No variable affects significantly on research skills.

3. No model is best suited to research skills.

\section{METHODOLOGY}

The design of this study is a quantitative data collection strategy that describes the relationship between a number and anything that can be quantified across multiple times or conditions. This design is concerned with quantifying and analyzing variables to obtain or generate results. It is a statistical technique used metaphorically to explain an issue or event through the collection of numerical data (Apuke 2017). Additionally, the causal method was used to ascertain the relationship between cause and effect. Variation in the observed independent variable is assumed to result in changes in the dependent variable (Bashin 2020). Thus, establishing a predicted relationship is a design characteristic of descriptive correlational studies. It determines the significant correlation between two or more variables using two or more data sets.

Additionally, this research focused on using data to develop successful models for reading, writing, learning strategies, and research abilities. As a result, a causal model was developed to explain the relationship between the overt and covert factors in the study (Hatami 2018). Additionally, the Structural Equation Model (SEM) can be used to help ensure the integrity of the product acquired as a result of the research method by emphasizing the following essential data required by the study to maintain proficiency in the study's outcomes through the following steps: defining the model, gathering data, estimating what needs to be modeled, modeling analysis, and possibly adjusting the study's actual progress in response to the study's overall outcome.

\section{SAMPLING DESIGN}

The study's design is based on a quantitative data collection technique that accurately describes the study's findings. A numerical relationship can be quantified through a systematic examination of various circumstances. To assess the level of research skills of 407 education students enrolled in public and private universities during the academic year of 2020-2021.

Thus, this research employs a structural model with a variety of fit indices used to determine sample size. However, some researchers assert that the structural model requires a minimum sample size of 200 and a maximum selection size of 400. (Ogunla, Ogunsami \& Oke 2012). On the other hand, (Karagoz 2016) stated that the structural model correlates with data from a theoretical model. In this regard, the structural model is more suitable for theory testing than other methods.

To ensure that the required number of participants from various private and public colleges and universities in Region X is obtained. Used Sloven's formula to calculate the number of students enrolled for the academic year 2020-2021 with a.05 level of significance, utilizing the stratified random sample technique with a total of 407 respondents. Respondents were chosen using a stratified and simple random sampling technique. Stratified sampling is a technique that divides the entire population into strata or categories. Simultaneously, simple random sampling is a technique for selecting a small sample from various strata to generate a generalization (Elfil and Negida 2017).

Thus, the researcher considers the 407 study participants who responded to the questionnaire regarding the scientific method used to select them. A stratified random sampling technique determined the number of college students enrolled in public and private colleges or universities in Region X. This means that each individual in a community, as well as the generated categories or strata, has an equal chance of being chosen as a study participant (Sharma 2017). Additionally, using stratified random sampling ensures that the results represent the entire population. The random number is generated at random from a number table or a created list of numbers (Taherdoost 2016).

As a result, participants in the study will come from several different colleges and universities throughout Region X. The latter is currently recruiting participants for the 2020-2021 academic year and will be recruited using a stratified random sampling technique.

\section{STATISTICAL DESIGN}

The following statistics must be used to evaluate the significant data collected adequately:

Mean. To determine the level of reading strategies; know the level of writing strategies; determine the level of learning strategies to develop the students' research skills.

Standard Deviation. It's a tool for determining the frequency distribution.

Pearson Product Moment Correlation. It assesses the relationship between reading, writing, learning strategies, and research skills.

Multiple Regression. It cultivates critical determinants of research skills.

Structural Equation Model. One requirement in this study is the use of SEM to research the best and most appropriate models. In analyzing the factors, an analysis of the researchers suggested a cut-off amount of 0.50 while (Ullman and Bentler 2006) used 0.45 to boost the culture of construction safety. The essence of the test, according to (Bentler \& Savalei 2010), is to ensure the elimination of properties with a low relationship with characteristics of other hidden factors in the last SEM. The cut-off cost is affected by the size of the sample, but a range of 0.45 to 0.50 is considered appropriate.

The goodness of Fit Statistics for Alternative Model through Analysis of Moment Structure (AMOS). Thus, it chooses the most appropriate model based on the following premise: Chi-Square/Degree of Freedom (CMIN/DF) 0.05 Normative Fit Index (NFI)>.95 Comparative Fit Index (CFI)>.95 The goodness of Fit Index (GFI)>.95 Tucker-Lewis Index>.95 Root Mean Square Error of Approximation (RMSEA).50

\section{GEOGRAPHICAL AREA}

This research was conducted in Region $\mathrm{X}$, commonly referred to as North Mindanao in the Philippines, covering 17,855 square kilometers. The entire region is comprised of the mountain province of Bukidnon in the south, Misamis Oriental in the north, 
Camiguin, a paradise island in the northeast, and Lanao del Norte and Misamis Occidental in the west. Cagayan de Oro, Guingoog, Iligan, Malaybalay, Ozamis, Oroquieta, Tangub, Valencia, and El Salvador are included. The region is comprised of 84 municipalities and 2,020 barangays. The region is comprised of plains, hills, mountains, and coastal areas, all of which have fertile soils abundant in minerals and agricultural resources.

Additionally, it is found in a variety of plants, springs, fish, and other seafood, as well as in water. It is a strategically important location that serves as a thoroughfare for Mindanao. Its beautiful marine facilities and roads contribute to the region's tourism.

In recent years, higher education institutions throughout the Philippines have been confronted with ensuring full participation and placing a premium on research and innovation. It already includes higher education institutions in Region $\mathrm{X}$ that are faced with similar challenges. According to some, the success of HEIs is anchored or reflected in students' and faculty members' ability to conduct and publish research in international journals. This is the requirement for measuring and achieving the capacity for new knowledge development in the modern era (Inovejas and Mirasol 2017). This location was chosen because the researcher desired to learn a variety of reading, writing, and learning strategies related to students' skills in region $\mathrm{X}$ that could be used to conduct any research activity.

\section{RESULTS}

The reading, writing, and learning strategies presented in this chapter represent a standard structural approach to research skills. The survey findings in this section demonstrate reading, writing, learning strategies, and a structural equation model approach to research skills. The data gathered as a result of the survey administered via questionnaire has been thoroughly analyzed to determine the variables derived from the indicators, such as reading strategies that will evaluate the level of indicators such as pre-reading strategies, during reading strategies, and post-reading strategies; will also include writing strategies that will assess the level of indicators such as pre-writing strategies, during reading strategies, and revision strategies; and will also have learning strategies that will evaluate the level of indicators such as planning stage, doing stage, reflection stage, how I know if I will succeed, why I want to do it well, and my feelings about the task, as well as the research skills as an independent variable which will evaluate the level of indicators such as reading and understanding research literature, collecting research data, programming skills, analyzing and interpreting research data, scientific communication, understanding of the field and the research process, and confidence in your research related abilities.

\section{Level of Reading Strategy}

Table 1 depicts the first variable, which is the level of reading strategy, which is comprised of three indicators: and with a total of thirty-four (34) statements, participants achieved a very high descriptive level, demonstrating that the reading strategy was always visible, with the pre-reading, during reading, and post-reading indicators all achieving a total standard deviation (SD) of 0.42 and a total mean score of 4.35 .

Table 1

Level of Reading Strategy

\begin{tabular}{|l|c|c|c|}
\hline \multicolumn{1}{|c|}{ Indicator } & SD & Mean & Descriptive Level \\
\hline Pre-reading strategies & 0.44 & 4.33 & Very High \\
\hline During-reading strategies & 0.45 & 4.34 & Very High \\
\hline Post-reading strategies. & 0.49 & 4.38 & Very High \\
\hline Total & $\mathbf{0 . 4 2}$ & $\mathbf{4 . 3 5}$ & Very High \\
\hline
\end{tabular}

The data shows that the first indicator in the reading strategy, pre-reading strategies, attained a very high descriptive level, indicating that they are constantly observed, with a standard deviation of 0.44 and a mean score of 4.33 . However, during reading strategies, the second indicator received a very high descriptive level, indicating that it was detected with a standard deviation of 0.45 and a mean score of 4.34. Meanwhile, the third indicator, post-reading methods, received a descriptive

very high level, indicating a very high frequency, with a standard deviation of 0.49 and a mean score of 4.35 .

\section{Level of Writing Strategy}

The second variable, based on data from the level of the writing strategy, contains three indicators: thirty-eight (38) statements that achieved a high descriptive level overall, confirming that writing strategy is frequently encountered. As a result of their efforts, they received a total standard deviation of 0.45 and a total mean score of 4.11 .

Table 2

Level of Writing Strategy

\begin{tabular}{|l|c|c|c|}
\hline \multicolumn{1}{|c|}{ Indicator } & SD & Mean & Descriptive Level \\
\hline Before I Start Writing/Pre-writing Strategies & 0.55 & 4.05 & High \\
\hline During-Writing Strategies & 0.44 & 4.35 & Very High \\
\hline Revision Strategies & 0.53 & 3.92 & High \\
\hline Total & $\mathbf{0 . 4 5}$ & $\mathbf{4 . 1 1}$ & High \\
\hline
\end{tabular}

With a standard deviation of 0.55 and a mean score of 4.05., the first indicator, pre-writing tactics, had a high descriptive level, indicating that pre-writing strategies are shared. However, the second indication was highly descriptive, with a standard deviation (SD) of 0.44 and a mean score of 4.35. As a result, the third indicator, revision tactics, was assigned a descriptive level of high, indicating that they were frequently recognized and received a standard deviation (SD) of 0.53 and a mean score of 3.92 .

\section{Level of Learning Strategy}

The level of learning strategy is depicted in Table 3, which includes six indicators and 37 statements. As a result, the study's findings on the degree of learning strategy have a descriptively high level of presentation, with a mean score of 4.09 and a total standard deviation (SD) of 0.42 . 
Table 3

Level of Learning Strategies

\begin{tabular}{|l|c|c|c|}
\hline \multicolumn{1}{|c|}{ Indicator } & SD & Mean & Descriptive Level \\
\hline Planning Stage & 0.50 & 4.17 & High \\
\hline Doing Stage & 0.51 & 4.29 & Very High \\
\hline Reflection Stage & 0.57 & 3.89 & High \\
\hline How I Know If I Will Succeed & 0.57 & 3.92 & Hery High \\
\hline Why I Want to Do It Well, & 0.53 & 4.31 & High \\
\hline My Feelings About the Task & 0.51 & 3.96 & High \\
\hline Total & $\mathbf{0 . 4 2}$ & $\mathbf{4 . 0 9}$ & \\
\hline
\end{tabular}

With a standard deviation of 0.50 and a mean score of 4.17, the first planning stage indication had a high descriptive level, indicating that the planning stage is typical. On the other hand, the second indicator performing stage had an extremely high descriptive level, with a standard deviation (SD) of 0.51 and a mean score of 4.29. As a result, the third indication reflection stage was classified as having a high descriptive level, indicating that it was frequently recognized, with a standard deviation (SD) of 0.57 and a mean score of 3.89 .

However, with a standard deviation (SD) of 0.57 and a mean score of 3.92 , the fourth indicator had a high descriptive level, indicating that it was frequently recognized. With a standard deviation (SD) of 0.53 and a mean score of 4.31 , the fifth indicator I want to emphasize had an extremely high descriptive quality.

Also, with a standard deviation (SD) of 0.51 and a mean score of 3.96, the sixth indicator had a high descriptive level, indicating that it was frequently noticed.

\section{Level of Research Skills}

The level of research skills, which included seven indicators and 38 statements, was descriptively high, with a total standard deviation (SD) of 0.54 and a mean score of 4.09 .

Table 4

Level of Research Skills

\begin{tabular}{|l|c|c|c|}
\hline \multicolumn{1}{|c|}{ Indicator } & SD & Mean & Descriptive Level \\
\hline Reading and Understanding Research Literature & 0.58 & 4.20 & Very High \\
\hline Collecting Research Data & 0.63 & 4.13 & High \\
\hline Programming Skills & 0.75 & 3.95 & High \\
\hline Analyzing and Interpreting Research Data & 0.63 & 4.11 & High \\
\hline Scientific Communication & 0.66 & 4.17 & High \\
\hline Understanding of the Field and the Research Process & 0.61 & 4.17 & High \\
\hline Confidence in Your Research Related Abilities & 0.67 & 3.93 & High \\
\hline Total & $\mathbf{0 . 5 4}$ & $\mathbf{4 . 0 9}$ & High \\
\hline
\end{tabular}

According to the data, the first reading and comprehension indicator achieved a very high descriptive level, indicating that reading and comprehension are always visible, with a standard deviation of 0.58 and a mean score of 4.20. The second indicator, which gathered research data, performed admirably descriptively, with a standard deviation of 0.63 and a mean score of 4.13. With a standard deviation (SD) of 0.75 and a mean score of 3.95 , the third indicator, programming skills, had a high descriptive level, indicating that they were frequently recognized.

On the other hand, the fourth indicator of research data analysis and interpretation was highly descriptive, indicating that it was frequently recognized, with a standard deviation (SD) of 0.63 and a mean score of 4.11. The fifth indicator of scientific communication demonstrated a high level of descriptive ability, with a mean of 4.17 and a standard deviation (SD) of 0.66 . The sixth indicator of field comprehension and research process, on the other hand, achieved a descriptively high level, indicating that they were frequently recognized, with a standard deviation (SD) of 0.61 and a mean score of 4.17. However, with a standard deviation (SD) of 0.67 and a mean score of 3.93, the seventh indicator of confidence in your research-related abilities had a high descriptive level, indicating that it was frequently observed.

\section{Significant Influence of Reading, Writing and \\ Learning Strategies on Research Skills}

The impact of reading, writing, and learning methodologies on research abilities is depicted in Table 5. The significant level of reading, writing, and learning techniques on research abilities was less than 0.05 , with a total F-value of 80.295 , an R-value of.615, an R2-value of.378, and a p-value of.000. The entire outcome favored rejecting the null hypothesis in favor of the alternative. 
Table 5

Significant Influence of Reading, Writing and Learning Strategies on Research Skills

\begin{tabular}{|c|c|c|c|c|c|}
\hline \multicolumn{6}{|l|}{ Research Skills } \\
\hline Exogenous Variables & & $B$ & $\beta$ & $t$ & Sig. \\
\hline Constant & & .071 & & .270 & .788 \\
\hline Reading Strategy & & .350 & .270 & 5.844 & .000 \\
\hline Writing Strategy & & .277 & .230 & 4.626 & .000 \\
\hline Learning Strategy & & .334 & .257 & 5.147 & .000 \\
\hline $\mathrm{R}$ & .615 & & & & \\
\hline $\mathrm{R}^{2}$ & .378 & & & & \\
\hline$\Delta \mathrm{R}$ & .374 & & & & \\
\hline $\mathrm{F}$ & 80.295 & & & & \\
\hline$\rho$ & .000 & & & & \\
\hline
\end{tabular}

The reading strategy has standardized and unstandardized coefficients., 350 and.270, respectively, and a t-value of 5.844 and a p-value of .000 (Significant); the writing strategy has standardized and unstandardized coefficients.277 and.230, respectively, and a t-value of 4.626 and a p-value of .000 (Significant); and the learning strategy has standardized and unstandardized coefficients of.334 and a t-value of 5.147 and a p-value of .000 (Significant).
The direct influence of the non-independent variable serves as a predictor that the variables and the non-independent variable can cooperate in traversing one or more variables. The latent variable between the indicators affected the endogenous variable research skills (p.05) by causing regression in reading, writing, and learning strategies.

Table 6

Direct and Indirect Effects of the Independent Variables on Research Skills of Best Fit Model

\begin{tabular}{lccc}
\hline \multicolumn{1}{c}{ Variables } & Direct Effect & Indirect Effect & Total Effect \\
\hline Reading Strategy & .345 & - & .345 \\
Writing Strategy & .319 & .394 & .713 \\
Learning Strategy & .399 & .141 & .540 \\
\hline
\end{tabular}

\section{Most Appropriate Model of Research Skills}

The final research question determines the optimal model for the factors that influence research abilities. Table 1 must be modified to comply with the goodness of fit requirements. The model developed in this study is summarized in Table 7 . To determine the most appropriate model, it is necessary to keep all indexes within the allowable range. The value of the Chi-square/degrees of freedom must be between 0 and 2 , with a p-value of at least 0.05 .

The Square Root of the Mean Error, the approximate value must be greater than or equal to
0.05 , and the p-close value must be greater than or equal to 0.05 . The Normed Fit Index, the Tucker-Lewis Index, the Comparative Fit Index and the Goodness of Fit Index must all exceed 0.90. The data-driven structural model 1 demonstrates the direct effect of exogenous variables such as reading, writing, and learning strategies and a causal relationship between endogenous variables such as research skills. As a result, this model is insufficient because all index values do not meet the criteria for each premise, $\mathrm{p}$ value $=.000 ;$ RMSEA $=.104$; and has a $p$-value of .000 . 
Table 7

Summary of Goodness of Fit Measures of the Five Generated Models

\begin{tabular}{|c|c|c|c|c|c|c|c|c|}
\hline Model & $\begin{array}{l}\text { P-value } \\
(>0.05)\end{array}$ & $\begin{array}{l}\text { CMIN / DF } \\
(0<\text { value }<2)\end{array}$ & $\begin{array}{c}\text { GFI } \\
(>0.95)\end{array}$ & $\begin{array}{c}\text { CFI } \\
(>0.95)\end{array}$ & $\begin{array}{c}\text { NFI } \\
(>0.95)\end{array}$ & $\begin{array}{c}\text { TLI } \\
(>0.95)\end{array}$ & $\begin{array}{c}\text { RMSEA } \\
(<0.05)\end{array}$ & $\begin{array}{l}\text { P-close } \\
(>0.05)\end{array}$ \\
\hline 1 & .000 & 5.323 & .816 & .879 & .856 & .862 & .104 & .000 \\
\hline 2 & .000 & 4.161 & .856 & .913 & .889 & .899 & .089 & .000 \\
\hline 3 & .000 & 3.640 & .866 & .928 & .904 & .965 & .081 & .000 \\
\hline 4 & .000 & 3.772 & .863 & .923 & .899 & .911 & .083 & .000 \\
\hline 5 & .055 & 1.259 & .969 & .995 & .977 & .993 & .026 & .999 \\
\hline end: & $\begin{array}{l}\text { CMIN/DF }-C \\
\text { GFI }-\mathrm{G} \\
\text { RMSEA }-R\end{array}$ & $\begin{array}{l}\text { quare/Degree } \\
\text { less of Fit Ind } \\
\text { Mean Square }\end{array}$ & Freed & & $\begin{array}{l}\text { NFI } \\
\text { TLI } \\
\text { CFI }\end{array}$ & $\begin{array}{l}\text { med Fit } \\
\text { ker-Lew } \\
\text { mparati }\end{array}$ & $\begin{array}{l}\text { lex } \\
\text { ndex } \\
\text { it Index }\end{array}$ & \\
\hline
\end{tabular}

The most established structural model 5 establishes a causal relationship between exogenous factors such as reading, writing, and learning strategies and endogenous variables such as research skills. As a result, as shown in Table 7 , the acceptability of the best-suited model is determined. The most acceptable model was Chi-Square divided by degrees of freedom, with a P-value of.055 and a 1.259 coefficient of determination. As a result, the Root Means Square of Error Approximation index of.026, which is less than the significant level with a P-value of.999 completely supports it. The Normed Fit Index, the Tucker Lewis Index, and Comparative Fit are among the other indexes. Thus, all dimensions are taken under the established standards. As demonstrated in Table 8, reading, writing, and learning methods all directly affect research abilities, although writing and learning strategies have an indirect effect. As a result, arrows from the predictor variable to the dependent variable are depicted in the image, where the non-independent variable flows directly through the other variables.

\section{SUGGESTION}

The researcher made the following recommendation based on the study's findings: develop a strong writing strategy, a strong learning strategy, and strong research skills. Additionally, the researcher recommends an opportunity to increase these three variables' levels significantly. Additionally, the three exogenous variables (reading, writing, and learning strategies) imply that students should be premium on these three variables. When the level of these variables rises, so do research abilities. According to the literature, there is a good chance that research skills will significantly improve if effective education, involvement, and strategies for learning literacy are maintained.

On the other hand, strengthening strategy training and providing feedback on improving writing strategy increases the likelihood that students will have excellent research skills. Additionally, it is critical to developing effective differentiated initiatives to enhance and expand the learning strategies of college students. Additionally, the student's research abilities are excellent as a result of their active learning strategies.
This section includes the following recommendations for reading, writing, learning strategies, and research skills: To begin, conduct a review of tertiary level teaching methods and skills related to research skills; second, develop a researchbased strategy to ensure the enhancement of research skills of teachers and students; third, enhance and develop teachers' and students' digital literacy as a critical 21st-century skill through attendance at training and workshops and exposure to/exploration of various digital technologies; fourth, improve the curriculum and conduct research. That is what this entails. Students are exposed to research subjects and activities as early as possible during their first year of college; fifth, mentoring programs at colleges and universities should be strengthened to assist students in developing into great researchers in their fields; sixth, colleges and universities should also provide appropriate incentives for students and faculty to research to increase their motivation to do so; and seventh, need to strengthen international relations and consortia in order to gain new knowledge and trends in conducting quality research. In other words, future researchers may consider additional predictor variables when determining the research skills necessary to conduct the study at Region X's public and private colleges and universities.

\section{CONCLUSION}

According to the study's findings regarding reading, writing, and learning strategies, the students' research abilities indicate that the overall results support the alternative hypothesis' rejection of the null hypothesis. In summary, this study developed a structural model that demonstrates the direct causal relationship between exogenous variables: reading, writing, and learning strategies and endogenous research skills variables. This research is based on constructivism theory, which established a theoretical framework for skills-based research based on the premise that people actively construct or create their knowledge. Your educational experiences and participation in activities and processes shape this reality. Constructivist learning theory, in turn, serves as the foundation for constructivist instruction. Constructivist education is based on the premise that learning occurs when students actively engage in the 
process of meaning-making. Rather than simply accepting information passively, the goal should be to expand one's knowledge. The creators of knowledge and meaning are the students. Constructivist instruction promotes critical thinking and helps students become motivated and self-sufficient (Bhattacharjee 2015).

Additionally, as proposed in the study by (Willison 2018), Models of Engaged Learning and Teaching (MELT), which are included in this special issue and elsewhere, are emerging frameworks that meet the criteria of the RSD. MELT is a tool for developing metacognitive and knowledge-based graduates with autonomous cognitive abilities to continue learning. They become increasingly curious, determined, discerning, harmonizing, creative, and constructive can help clarify the purpose of higher education.

\section{REFERENCES}

1. Akuegwu, Basil A. and Nwi-ue, Felix D. (2018). Assessing Graduate Students' Acquisition of Research Skills in Universities in Cross River State Nigeria for Development of The Total Person. European Journal of Research and Reflection in Educational Sciences, 6(5), 29-44, ISSN 2056-5852

2. Apuke, Oberiri Destiny. (2017). Quantitative Research Methods: A Synopsis Approach. Kuwait Chapter of Arabian Journal of Business and Management Review, 6(10), 40-47, https://doi.org/10.12816/0040336.

3. Bhasin, Hitesh. (2020). Causal Research - Meaning, Explanation, Examples, Components. "Marketing91.

4. Bhattacharjee, Jayeeta. (2015). Constructivist Approach to Learning- An Effective Approach of Teaching Learning. International Research Journal of Interdisciplinary \& Multidisciplinary Studies (IRJIMS), 1(6), 65-74.

5. Bentler, Peter \& Savalei, Victoria (2010). "Analysis of correlation structures: Current status and open problems." In S. Kolenikov, D. Steinley, \& L. Thombs (Eds.), Statistics in the Social Sciences (2010): (pp. 136).

6. Castillo-Martínez, Isolda Margarita and RamírezMontoya, María Soledad. (2021). Research Competencies to Develop Academic Reading and Writing: A Systematic Literature Review. Frontiers in Education, 5, 1-12. https://doi.org/10.3389/feduc.2020.576961.

7. Deraney, Philline and Hamdan Alghamdi, Amani K. (2018). Teaching Research Skills to Undergraduate Students Using an Active Learning Approach: A Proposed Model for Preparatory-Year Students in Saudi Arabia. International Journal of Teaching and Learning in Higher Education, 30(2), 184-194.

8. Dorimana, Aline., Ndihokubwayo, Kizito and Uworwabayeho, Alphonse. (2021). Doctoral Student Research Skills: Case of the University of RwandaCollege of Education. Rwandan Journal of Education, 5(1), 4-20.

9. Elfil, Mohamed and Negida, Ahmed. (2017). Sampling methods in Clinical Research; an Educational Review. Emergency (Tehran, Iran), 5(1), 1-3.

10. Ezugwu G. and Jebson, Sofeme R. (2019). Evaluation of Research Skills Application Among Colleges of Education Lecturers in Kaduna State. International Journal of Interdisciplinary Research Methods, 6(5), 40-51.

11. Gyuris, Emma. (2018). Evaluating the effectiveness of postgraduate research skills training and its alignment with the Research Skill Development framework Journal of University Teaching \& Learning Practice, 15(4), 118,https://doi.org/10.14453/jutlp.v15i4.5

12. Hatami, R. (2018). Development of a protocol for environmental impact studies using causal modeling. Water Res. 138, 206-223.

13. Inovejas, Christian and Mirasol, Joy. (2017). Building A Culture of Research in A Higher Education
Institution. Journal of Higher Education Research, 2(1), 72-82.

14. Karagöz, Y. (2016). SPSS ve AMOS 23 Uygulamal Istatistiksel Analizler. Ankara: Nobel.

15. Nauman, Sarwat. (2017). Lack of Critical Thinking Skills Leading to Research Crisis in Developing Countries: A Case of Pakistan. Learned Publishing, 30(3), 233-236, doi:10.1002/leap.1091.

16. Ogunlana, Stephen., Ogunsami, Deji Rufus and Oke, Ayodeji Emmanuel. (2015). Establishing a Common Ground for the Use of Structural Equation Modelling for Construction Related Research Studies. Construction Economics and Building, 12(3), 89-94, https://doi.org/10.5130/ajceb.v12i3.2658.

17. Sharma, Gaganpreet. (2017). Pros and cons of different sampling techniques. International Journal of Applied Research, 3(7): 749-752.

18. Taherdoost, Hamed. (2016). Sampling Methods in Research Methodology; How to Choose a Sampling Technique for Research. SSRN Electronic Journal, 5(2), 18-27, doi:10.2139/ssrn.3205035.

19. Ullman, J. (2006). "Structural equation modeling." In B. G. Tabachnick \& L. S. Fidell Eds.), Using multivariate statistics, (5th ed.;(2006) pp. 653-771). Boston: Allyn \& Bacon

20. Willison, John W. (2018). Research Skill Development Spanning Higher Education: Critiques, Curricula and Connections. Journal of University Teaching and Learning Practice, 15(4), Oct. 2018, 2-16, https://doi.org/10.53761/1.15.4.1. 